\title{
A structural model of safety and safety regulation in the truckload trucking industry
}

\author{
Ian Savage* \\ Department of Economics and the Transportation Center, Northwestern University, 2001 \\ Sheridan Road, Evanston, IL 60208, USA \\ Published in Transportation Research Part E (The Logistics \\ and Transportation Review) Volume 47:2 (March 2011), pages 249-262
}

\begin{abstract}
This paper models public policies to improve safety within a structural model of the truckload trucking industry. The policies are designed to ameliorate the market failures associated with the myopic ignoring of crash costs by some trucking firms, and institutional constraints that prevent full internalization of the costs of crashes. The paper compares two alternative public policies: (1) levying post-crash fines and making shippers bear secondary liability for damages incurred in crashes, and (2) imposition of a minimum safety standard, in conjunction with a requirement to hold insurance, and assessing penalties for non-compliance with the standard.
\end{abstract}

Keywords: trucking, externalities, safety, standards, liability

\section{RESEARCH HIGHLIGHTS}

- Builds a structural model of trucking price, quantity and level of safety

- Shows that different commodities will be transported at different levels of safety

- Illustrates the effects of myopic decision making and uncompensated externalities

- Compares different policy responses including imposing minimum safety standards

- Discusses how policy choice in a political economy may be non-optimal

* e-mail: ipsavage@northwestern.edu 


\section{Introduction}

There is an extensive empirical literature on the economics of truck safety (see for example, Saccomanno and Shortreed, 1996, and the references cited within). In general this literature can be thought of as describing or estimating reduced form equations. Papers have addressed questions such as whether specific characteristics of firms (size, private versus for-hire ownership, the commodity carried) correlate with safety performance, whether quality is related to costs, and whether specific safety regulations have been effective in reducing the rate of crashes. What has been lacking is a structural framework within which to interpret the safety choices by shippers and trucking firms, and the mechanisms by which safety regulations might affect safety performance, the prices charged by trucking firms and quantities shipped. Papers that have addressed this issue, such as Moses and Savage (1997), have used simplistic assumptions that were not framed in a structural context.

There is no shortage of suitable structural models. An extensive theoretical literature appeared in the mainstream economics literature in the mid to late 1970s dealing with the determinants of product quality under different market structures, the effects of various types of market failures, and the mechanisms for intervention to remediate these failures (see Shavell, 2004, for an extensive theoretical review; and Savage, 1999, in the context of transportation safety).

This paper describes an equilibrium structural model of the truckload trucking industry. ${ }^{1}$ Within this model the effects of the two leading safety market failures in this industry are analyzed. The first is uncompensated externalities inflicted on bystanders in crashes, and the second is myopic behavior by some trucking firm managers who ignore the possibility that their actions increase the risk of crashes occurring. ${ }^{2}$ The paper then models the effects of various public policy options to ameliorate these failures. The models define which parties gain and which lose under each policy, and hence provide insight into the policy that will find favor in the political economy.

\section{Structural Model}

\subsection{Geography, Market Structure and Time Horizon}

The geography of the model is that there are two locations, A and B, which are located at such a distance from each other that truck is the preferred mode to move commodities. Commodities are produced at A and consumed at B. ${ }^{3}$ Manufacturers, who we will call "shippers," contract with trucking firms ("carriers") to move the commodities to the consumers. Consumers purchase directly from the shippers and pay a price that compensates for both the manufacturing and transportation costs. There are numerous shippers and consumers, so there is perfect competition in the trade between shippers and consumers. The genesis for this model is Samuelson's (1952) classic analysis of inter-regional and international trade. The paper uses models that have a stationary equilibrium, and the results are presented for one representative time period. The length of a time period is equivalent to that for a commodity to be shipped from A to B and purchased by the ultimate consumer. 


\subsection{Shippers}

A set of heterogeneous independent commodities, denoted by subscript $j$, is produced competitively at a constant marginal cost denoted by $M_{j}$, with no fixed costs. For notational simplicity, we will assume that each unit of $j$ is equivalent to an entire truckload. It is an easy extension of the model, and one that does not affect the conclusions, to specify that a truckload contains a certain number of units of $j$ that are then sold to individual consumers.

\subsection{Carriers}

Carriers are assumed to be solely responsible for the production of safety. ${ }^{4}$ Of course, many truck-involved crashes are "caused" by the negligent actions of other road users. Our model assumes that risky behavior by automobile drivers is, like the weather, an environmental factor common to all carriers. All other things being equal, the superior quality of the drivers and the equipment employed by safer carriers are more effective in mitigating this environmental risk.

Within each time period, costs are potentially incurred at two points. First, prior to departing from location A, the carrier has to incur the cost of basic transportation and the "preventive effort" undertaken to ensure a given level of safety. The basic transportation and prevention costs have to be incurred every time period. Carriers can reduce their crash rate by hiring higher-quality drivers, ensuring that these drivers do not become fatigued, purchasing more safety features for their trucks, and making sure that the trucks are properly maintained. These costs are an increasing convex function $l_{j}(S)$, where $S$ is our measure of safety and is defined as unity minus the probability that a crash occurs during one trip from A to B (which is to say, in the current time period). The preventive cost function may vary across commodities. For example, tanker trucks may require more preventive expenditures to obtain a given safety level than do box trailers.

The second point at which costs may be incurred is during the trip from A to B. If a crash occurs, with probability $(1-S)$, the carrier suffers private harms $H_{j}$ which represents the net present value of items such as vehicle damage, lost staff productivity and staff medical expenses. Some types of cargoes, such as hazardous materials, may contribute to greater private physical and health damages. The cargo will suffers loss or damage denoted by $D_{j}$, which also includes the cost of moving a replacement unit of the commodity to the consumer. In some countries, such as the United States, common carriers are strictly liable to compensate shippers for cargo loss or damage while it is in the carrier's possession. Finally, the net present value of the total harm, or externality, that bystanders such as other road users and those who live or work close to the highway suffer in each crash is denoted as $E_{j}$. The externalities are substantial. Only $15 \%$ of the fatalities in truck-involved crashes in the United States are truck occupants. Releases of hazardous materials can impose widespread harms and are associated with substantial clean up costs.

The market failure due to uncompensated externalities is modeled by specifying that exogenous legal structures are such that only a proportion of the externality, denoted by $\alpha_{j}$, is legally recoverable from carriers. This proportion may vary by commodity depending on the types of externalities that specific commodities generate. Examples of unrecoverable harms include travel 
delays caused to vehicles caught up in the congestion at a crash site, and costs incurred by public agencies such as police and fire departments.

The other market failure is modeled by specifying that carriers are of two types: "regular carriers" denoted by subscript 2 , and "myopic carriers" denoted by subscript 1 . Individual carriers are exogenously predetermined as to type, and there are numerous potential carriers of each type. Consequently there is perfect competition between carriers of each type in their dealings with shippers.

Each carrier makes at most one trip carrying one particular commodity in each time period. The total expected per period cost function for a regular carrier carrying commodity $j$, denoted by $c_{j 2}(S, \alpha)$, is given by:

$$
c_{j 2}(S, \alpha)=l_{j}\left(S_{j 2}\right)+\left(1-S_{j 2}\right)\left(H_{j}+D_{j}+\alpha_{j} E_{j}\right) .
$$

A regular carrier will recognize that it will need to price in such a way so as collect a premium over prevention costs on each trip and place it into a fund that can be used to cover costs that occur as a result of a crash. Carriers can either manage this fund themselves (self insurance) or purchase insurance policies. We will assume that fair insurance policies can be purchased that have zero administration costs and have premiums tailored to the risks posed by specific commodities.

Myopic carriers carrying commodity $j$ have an expected per period cost function given by:

$$
c_{j 1}(S)=l_{j}\left(S_{j 1}\right)+\left(1-S_{j 1}\right) H_{j}
$$

One might argue that a true myopic carrier will even ignore the private harms to itself. However, this has the modeling implication that a myopic carrier would choose zero preventive effort, which clearly is not consistent with the real world. In practice, myopic carriers exist because bankruptcy law can protect them from claims by shippers and bystanders. Many small owner-operators will directly bear and will be acutely aware of the probability of private harms from crashes because destruction of their vehicle will eliminate one of their largest personal assets, and a personal injury would prevent them from earning a living either in trucking or in some alternative occupation. Myopic carriers are assumed to purchase fair insurance policies, with no administrative costs, to cover medical and disability expenses and to make the providers of vehicles (be they leasing companies or banks making loans) whole. For the purposes of this paper, these expenses are settled prior to any (unsuccessful) claims by shippers and bystanders.

\subsection{Carrier Safety Choice}

As the trucking market is competitive, both types of carriers will select a level of safety that minimizes their expected costs in the time period. For regular carriers, the $c_{j 2}(S, \alpha)$ function and its components are illustrated in Figure 1. The level of safety is shown on the horizontal axis, with low levels of safety at the left-hand end and high levels of safety at the right-hand end. As a consequence of the linear nature of the harm, cargo damage, and compensated externality functions 
and the convex nature of the prevention cost function, the $c_{j 2}(S, \alpha)$ function takes on a " $U$ " shape. The cost-minimizing safety choice is denoted as $S_{j 2}{ }^{\#}$, and defined by the first order condition:

$$
\partial \mathrm{c}_{j 2} / \partial S_{j 2}=l_{j}^{\prime}(S)-H_{j}-D_{j}-\alpha_{j} E_{j}=0
$$

At the cost-minimizing level of safety, the slope of the prevention cost curve is equal to the sum of the harms suffered by the carrier, the cargo, and the compensated harm to bystanders in a crash (the latter is the slope of the combined private harm, cargo damage and compensated externality function in Figure 1).

Myopic carriers will minimize their costs by selecting a level of safety denoted as $S_{j 1}$, according to the first order condition:

$$
\partial \mathrm{c}_{j 1} / \partial S_{j 1}=l_{j}^{\prime}(S)-H_{j}=0
$$

A comparison of equations (3) and (4) shows, not surprisingly, that $S_{j 2}{ }^{\#}>S_{j 1}{ }^{\#}$ so that myopic carriers of a specific commodity will select a lower level of safety than regular carriers of that commodity.

\subsection{Inter-Commodity Variation}

If we restrict our attention to regular carriers for a moment, we can obtain some insights into how the cost-minimizing safety level will vary between commodities due to differences in $l_{j}{ }^{\prime}(S), H_{j}$, $D_{j}$ and $\alpha_{j} E_{j}$. Modifying Figure 1 to represent a commodity with higher levels of $H_{j}, D_{j}$ and/or $\alpha_{j} E_{j}$ will require moving the intercept of the private harm, cargo damage and compensated externality function upwards, and pivoting the function around its right-hand $\left(S_{j}=1\right)$ end. Consequently the $c_{j 2}(S, \alpha)$ function will also pivot upward around its right-hand end. If $H_{j}, D_{j}$ and/or $\alpha_{j} E_{j}$ increase in equation (3), at the optimum there must be a larger $l_{j}^{\prime}(S)$. With a convex prevention cost function, this will only occur at a higher level of safety.

Conversely, if a commodity incurs a steeper prevention cost function than that illustrated in Figure 1, the optimal level of safety will occur at a lower level of safety. However, the issue is not entirely clear cut in that the types of commodities that incur the steepest prevention cost curves tend to be particularly delicate or hazardous commodities that also are associated with particularly high values of $H_{j}, D_{j}$ and/or $\alpha_{j} E_{j}$

The implication is that commodities that have a high value and/or are more likely to be damaged in a crash will be moved by carriers that have higher levels of safety. The same is true for commodities, such as hazardous materials, that would impose great potential externalities on bystanders in a crash. In contrast benign, robust and low value commodities will be carried at a lower level of safety.

Empirical evidence on crash rates by commodity is sparse. A study by Horrace and Keane (2004) did find some significant differences that are consistent with these theoretical insights. Carriers hauling grain, livestock feed, coal, coke, and fresh produce had the worst crash rates. All of 
these products have one or more of the physical characteristics that they are generally not hazardous, have a low value, and/or are resilient to damage in a crash.

\subsection{Carrier Reputation and Pricing}

For each commodity, shippers will only have a meaningful choice of carriers if myopic carriers, who offer lower safety, also have lower costs than regular carriers. From the point of view of the shipper, contracting with a myopic carrier raises the possibility that the shipper will not be reimbursed by the carrier for crash-related cargo damage. The shipper will therefore implicitly have to make provision to self-insure against the expected cargo loss of $\left(1-S_{j 1}{ }^{*}\right) D_{j}$ on each trip. A necessary condition for the existence of myopic carriers for a specific commodity will be that:

$$
l_{j}\left(S_{j 1}{ }^{*}\right)+\left(1-S_{j 1}{ }^{*}\right) H_{j}+\left(1-S_{j 1}{ }^{*}\right) D_{j}<l_{j}\left(S_{j 2}{ }^{*}\right)+\left(1-S_{j 2}{ }^{*}\right)\left(H_{j}+D_{j}+\alpha_{j} E_{j}\right) .
$$

Adding $\left(1-S_{j 1}{ }^{\#}\right) \alpha_{j} E_{j}$ to both sides of the inequality and rearranging, produces:

$$
l_{j}\left(S_{j 1}{ }^{*}\right)+\left(1-S_{j 1}{ }^{*}\right)\left(H_{j}+D_{j}+\alpha_{j} E_{j}\right)-l_{j}\left(S_{j 2}{ }^{*}\right)-\left(1-S_{j 2}{ }^{*}\right)\left(H_{j}+D_{j}+\alpha_{j} E_{j}\right)<\left(1-S_{j 1}{ }^{*}\right) \alpha_{j} E_{j},
$$

or, alternatively stated:

$$
c_{j 2}\left(S_{j 1}{ }^{\#}, \alpha_{j}\right)-c_{j 2}\left(S_{j 2}{ }^{\#}, \alpha_{j}\right)<\left(1-S_{j 1}{ }^{\#}\right) \alpha_{j} E_{j} .
$$

The increased expected total costs from selecting the non-cost minimizing safety level of $S_{j 1}{ }^{\#}$ rather than $S_{j 2}{ }^{\#}$ must be smaller than the magnitude of the expected compensation for externalities that myopic carriers (and hence their shippers) default on paying. Holding everything else constant, commodities generating large externalities are more likely to provide fertile ground for myopic behavior.

Assuming that this necessary condition is met, a stationary equilibrium set of transportation prices, or "rates," can be defined for both regular and myopic carriers using the seminal models of Klein and Leffler (1981) and Shapiro (1983). These authors developed models of competitive vertical differentiation in product quality. They described a process by which some firms supply low quality (myopic carriers in our context) while others choose to invest to establish a reputation for high quality (regular carriers). Carriers establishing a reputation as a regular carrier incur an initial loss because they have to price consistent with myopic carriage until shippers recognize that a higher quality service is being provided. Shippers are then willing to pay a higher rate. We will assume that the length of time necessary to establish a reputation is just one period. As soon as the reputation is revealed it becomes common knowledge to all shippers. Carriers that have established a reputation as a regular carrier price such that they earn a premium over cost that is just sufficient to repay over time their initial investment.

In theory, carriers could milk a reputation by "cheating" and deceiving shippers. Cheaters could earn a profit until shippers become aware, one period later, that they have been exploited. Because the cheating becomes common knowledge, cheaters have to forgo the future rate premiums associated with a high quality reputation. While the Klein and Leffler / Shapiro models set up a 
formal structure to analyze reputation formation and destruction, competitive equilibrium in these models is such that no carriers have any incentive to actually cheat. Consequently, the expectations of shippers who employ regular carriers are always fulfilled.

In these models, the equilibrium rate charged by myopic carriers, denoted as $t_{j 1}$, is driven down by free entry to the carrier's cost:

$$
t_{j 1}\left(S_{j 1}{ }^{*}\right)=c_{j 1}\left(S_{j 1}{ }^{*}\right)=l_{j}\left(S_{j 1}{ }^{*}\right)+\left(1-S_{j 1}{ }^{\#}\right) H_{j}
$$

Free entry also ensures that the rate premium charged by regular carriers is only just sufficient to recoup their initial investment in establishing a reputation. (In equilibrium, this rate is also just sufficient to dissuade them from milking their reputation.) Following Shapiro (1983), and denoting the per-period discount rate as $r$, the equilibrium rate for regular carriers is given by:

$$
\begin{aligned}
t_{j 2}\left(S_{j 1}{ }^{\#}, S_{j 2}{ }^{\#}, \alpha_{j}\right)=c_{j 2}\left(S_{j 2}{ }^{\#}, \alpha_{j}\right)+r\left[c_{j 2}\left(S_{j 2}{ }^{\#}, \alpha_{j}\right)-t_{j 1}\left(S_{j 1}^{\#}\right)\right]=l_{j}\left(S_{j 2}{ }^{\#}\right)+\left(1-S_{j 2}{ }^{\#}\right)\left(H_{j}+D_{j}+\alpha_{j} E_{j}\right) \\
+r\left[l_{j}\left(S_{j 2}{ }^{\#}\right)+\left(1-S_{j 2}\right)\left(H_{j}+D_{j}+\alpha_{j} E_{j}\right)-l_{j}\left(S_{j 1}{ }^{\#}\right)+\left(1-S_{j 1}{ }^{\#}\right) H_{j}\right] .
\end{aligned}
$$

\subsection{Consumers}

For each commodity $j$, there are numerous consumers, denoted by subscript $i$, who desire to purchase at most one unit in each time period. Therefore an individual's consumption of $j$ is defined as $J \in\{0,1\}$. Consumers have per-period incomes of $K_{i}$ and their utility depends on their consumption of commodity $j$, and the composite of the other goods they can purchase with the remainder of their income.

Consumers' valuation of $j$ is composed of two parts. First, we define $v_{j} \in\left[\mathrm{v}_{j}^{\text {min }}, \mathrm{v}_{j}^{\text {max }}\right]$ that measures the intensity of preference from consuming a unit of commodity $j$. This valuation is distributed across the consumers according to the function $F_{j}\left(v_{j}\right)$. Second, a crash will damage or destroy the cargo, and the affected consumer will suffer a time penalty from having to wait until the next time period to obtain a replacement shipment. Let us define $\theta_{j} \in\left[\theta_{j}^{\min }, \theta_{j}^{\text {max }}\right]$ that measures a consumer's intensity of preference for "reliability of delivery," which can be interpreted as their preference for immediate rather than delayed gratification. We will assume that $\theta_{j}$ is distributed across consumers according to the function $G_{j}\left(\theta_{j}\right)$, which is independent of the distribution $F_{j}\left(v_{j}\right)$.

Consistent with the standard competitive inter-regional trade model, the delivered price to the consumer is the sum of the manufacturing cost and the transportation rate. Consumers who wish to consume a commodity can select to either have it delivered by a regular carrier or by a myopic carrier. In equilibrium, delivery by a regular carrier is associated with a price, denoted by $p_{j 2}$, of:

$$
p_{j 2}\left(S_{j 1}{ }^{\#}, S_{j 2}{ }^{\#}, \alpha_{j}\right)=M_{j}+t_{j 2}\left(S_{j 1}{ }^{\#}, S_{j 2}{ }^{\#}, \alpha_{j}\right)
$$

with delivery reliability described by $S_{j 2}$. The delivered price by a myopic carrier will be given by:

$$
p_{j 1}\left(S_{j 1}{ }^{\#}\right)=M_{j}+\left(1-S_{j 1}{ }^{\#}\right) D_{j}+t_{j 1}\left(S_{j 1}{ }^{\#}\right)=M_{j}+l_{j}\left(S_{j 1}{ }^{\#}\right)+\left(1-S_{j 1}{ }^{\#}\right)\left(D_{j}+H_{j}\right) \text {, }
$$


with delivery reliability described by $S_{j 1}{ }^{\#}$. Note that the shipper is inherently having to self-insure against cargo loss, and passes this expected cost along to the consumer. The necessary condition described in equation (5) ensures that the delivered price by regular carriers exceeds the delivered price by myopic carriers.

We specify a convenient separable, quasi-linear form for a utility function. If a consumer decides not to purchase any of commodity $j$, denoted by subscript 0 , she will earn a utility of:

$$
U_{i j 0}=K_{i}
$$

If she purchases the commodity and it is delivered by a regular carrier, her utility will be:

$$
U_{i j 2}=v_{i j}+\theta_{i j} S_{j 2}+K_{i}-p_{j 2},
$$

and if the delivery is by a myopic carrier, her utility will be:

$$
U_{i j 1}=v_{i j}+\theta_{i j} S_{j 1}+K_{i}-p_{j 1}
$$

\subsection{The Demand for Trucking}

We can define the point where consumers are indifferent between carrier types by setting equation (13) equal to equation (14). Rearranging this equality produces the critical value, $\theta_{j 12}$ for which consumers are just indifferent:

$$
\theta_{j 12}=\frac{p_{j 2}-p_{j 1}}{S_{j 2}-S_{j 1}}
$$

Consumers with larger values of $\theta_{j}$ prefer to purchase the commodity transported by regular carriers rather than that transported by myopic carriers, regardless of their value of $v_{j}$.

Equating equations (12) and (13) and rearranging terms yields the following boundary condition characterizing the values of $v_{j}$ and $\theta_{j}$ for which consumers are indifferent between purchasing the commodity that is transported by a regular carrier and not purchasing at all:

$$
v_{j 02}(\theta)=p_{j 2}-S_{j 2} \theta_{j}
$$

For any given value of $\theta_{j}$, consumers with a $v_{j}$ greater than $v_{j 02}(\theta)$ prefer to buy the commodity that is delivered by a regular carriers rather than make no purchase. Similarly, we can define:

$$
v_{j 01}(\theta)=p_{j 1}-S_{j 1} \theta_{j}
$$

For any given value of $\theta_{j}$, consumers with a $v_{j}$ greater than $v_{j 01}(\theta)$ prefer to buy the commodity that is delivered by a myopic carrier rather than make no purchase. 
The demand system is illustrated in Figure 2, indicating the consumption choices of individual consumers whose $\left(v_{j}, \theta_{j}\right)$ values lie in different regions of the figure. Consumers in regions III and IV purchase the commodity delivered by regular carriers. The total demand for regular carrier trips is given by:

$$
q_{j 2}=\int_{\theta_{j 12}}^{\theta_{j}^{\max }}\left[\int_{v_{j 02}\left(\theta_{j}\right)}^{v_{j}^{\max }} f_{j}\left(v_{j}\right) d v_{j}\right] g_{j}\left(\theta_{j}\right) d \theta_{j}
$$

where $f_{j}\left(v_{j}\right)$ and $\mathrm{g}_{j}\left(\theta_{j}\right)$ are the density functions associated with $F_{j}\left(v_{j}\right)$ and $\mathrm{G}_{j}\left(\theta_{j}\right)$. Consumers in regions I and II purchase the commodity delivered by myopic carriers. Myopic carriers have a total demand given by:

$$
q_{j 1}=\int_{\theta_{j}^{\min }}^{\theta_{11}}\left[\int_{v_{j 11}\left(\theta_{j}\right)}^{v_{j}^{\max }} f_{j}\left(v_{j}\right) d v_{j}\right] g_{j}\left(\theta_{j}\right) d \theta_{j}
$$

Consumers in regions $\mathrm{V}$ and VI do not purchase. This demand system can be quantified given $\alpha_{j}$ and the equilibrium values of $S_{j 1}{ }^{\#}$ and $S_{j 2}{ }^{\#}$, which then determine delivered consumer prices though equations (10) and (11).

Clearly there would be a sizeable market opportunity for myopic carriage of a specific commodity if a large proportion of the potential customers are very insensitive to obtaining the commodity in a reliable fashion. This is to say that $\theta_{j}^{\text {min }}$ is small, and the distribution of values of $\theta_{j}$ is skewed towards the lower end of the range. An example may be the haulage of wastes where the customers are landfill operators who presumably have very little sensitivity as to whether a particular shipment arrives on schedule. In contrast, commodities such as components that are being delivered to manufacturing plants operating with a "just in time" supply chain would generate little or no demand for myopic carriers.

\subsection{The Effect on Bystanders}

In equilibrium, the total expected uncompensated externality (TEUE) imposed on bystanders will be given by the sum over all commodities of the entire externality imposed by myopic carriers, plus the portion of the externality generated by regular carriers that is not legally recoverable:

$$
\operatorname{TEUE}\left(S_{j 1}^{\#}, S_{j 2}^{\#}, \alpha_{j}\right)=\sum_{j}\left[E_{j} q_{j 1}\left(S_{j 1}^{\#}, S_{j 2}^{\#}, \alpha_{j}\right)+\left(1-\alpha_{j}\right) E_{j} q_{j 2}\left(S_{j 1}^{\#}, S_{j 2}^{\#}, \alpha_{j}\right)\right] .
$$

\section{Modeling Fines and Secondary Liability}

The first public policy countermeasure that we will analyze gets directly to the heart of the problem, and removes the market failure entirely. ${ }^{5}$ It consists of a post-crash fine to cover uncompensated externalities, and a change in liability laws to ensure that shippers share in the risks. Shippers are assigning secondary liability, and would be liable for any proportion of the fine and compensated externality that the carrier is unable to cover. 
The rationale for a fine is that some externalities, such as delays to road users at crash sites, cannot practically be litigated due to the large number of plaintiffs and the relative small size of each individual's loss. However, it would be possible for the government to assess a fine of $\left(1-\alpha_{j}\right) E_{j}$ when a crash occurs. The size of the fine will vary by commodity, depending on the typical size of the uncompensated externality that the commodity causes. The practical advantage of this policy is its ex-ante nature, whereby the nature of the commodity carried is revealed as a result of the crash, and the fine can be tailored accordingly.

The fine effectively means that $\alpha_{j}=1$, and regular carriers will plan for, and internalize the full cost of crashes. Equation (1) will be modified to:

$$
c_{j 2}(S, \alpha=1)=l_{j}\left(S_{j 2}\right)+\left(1-S_{j 2}\right)\left(H_{j}+D_{j}+E_{j}\right),
$$

and regular carriers will select a cost minimizing level of safety, denoted as $S_{j 2}{ }^{*}$, from the first order condition:

$$
\partial \mathrm{c}_{j 2} / \partial S_{j 2}=l_{j}^{\prime}\left(S_{j 2}\right)-H_{j}-D_{j}-E_{j}=0
$$

Comparing equations (22) and (3) allows us to conclude that $S_{j 2}{ }^{*}>S_{j 2}{ }^{\#}$.

Myopic carriers, of course, do not care about the fine, and will continue to select a cost minimizing level of safety, $S_{j 1}$, given by equation (4). The shipper not only has to pay the rate for the myopic carrier, and bears the expected cost of the cargo loss as before, but is now also liable for the expected externality. The total cost to the shipper is now:

$$
t_{j 1}\left(S_{j I}{ }^{\#}\right)+\left(1-S_{j 1}{ }^{\#}\right)\left(D_{j}+E_{j}\right)=c_{j l}\left(S_{j 1}{ }^{\#}\right)+\left(1-S_{j 1}{ }^{\#}\right)\left(D_{j}+E_{j}\right)=c_{j 2}\left(S_{j 1}{ }^{\#}, \alpha=1\right)>c_{j 2}\left(S_{j 2}{ }^{*}, \alpha=1\right) .
$$

The shipper is now bearing the same type of costs that it would if it employed a regular carrier. However, the myopic carrier will select a lower, non-cost minimizing, safety level than a regular carrier. Myopic carriers will be eradicated from the market because they are offering a lower probability of reliable delivery at a higher overall cost compared with regular carriers. Shippers will have no incentives to employ myopic carriers.

Because there is now only one type of carrier, it is unnecessary to specify a reputation model. Consequently, entry and competition will force the rate charged by regular carriers down to cost. ${ }^{6}$ The price charged to consumers will be:

$$
p_{j 2}\left(S_{j 2}{ }^{*}, \alpha=1\right)=M_{j}+c_{j 2}\left(S_{j 1}{ }^{*}, \alpha=1\right) .
$$

We cannot tell definitively whether this price is greater than or less than the price charged for delivery by regular carriers in the face of market failures. On one hand, it is no longer necessary to charge a rate premium over cost because carriers do not incur any initial investment to establish a reputation. On the other hand the costs of regular carriers are now higher than when they did not have to cover all of the externality costs. The price change will be given by: 


$$
\begin{gathered}
p_{j 2}\left(S_{j 2}{ }^{*}, \alpha=1\right)-p_{j 2}\left(S_{j 1}{ }^{\#}, S_{j 2}{ }^{\#}, \alpha_{j}\right)=\left(1-S_{j 2}{ }^{\#}\right)\left(1-\alpha_{j}\right) E_{j}+\left[c_{j 2}\left(S_{j 2}{ }^{*}, \alpha=1\right)-c_{j 2}\left(S_{j 2}{ }^{\#}, \alpha=1\right)\right] \\
-r\left[c_{j 2}\left(S_{j 2}{ }^{\#}, \alpha_{j}\right)-t_{j 1}\left(S_{j 1}{ }^{*}\right)\right] .
\end{gathered}
$$

The first term on the right-hand side is the expected fine at the level of safety associated with the market failures, the second term will be negative and is the cost reduction due to the carrier moving to the cost minimizing level of safety (after the institution of the fine), and the third term is the disappearance of the rate premium that was originally necessary to offset the initial investment to establish a reputation.

The effect on the demand system can be illustrated using Figure 2. Because regular trucking is the only option to survive in the market place, only the $v_{j 02}(\theta)$ frontier is relevant. Consumers above and to the right will purchase the commodity delivered by regular carriers, and those below and to the left will not consume the commodity. But this frontier has shifted compared with the equilibrium with market failures. The intercept term will shift up or down depending on whether the price associated with regular carriage increases or decreases, and the slope of the frontier becomes steeper because regular carriers now offer higher levels of reliability. Consequently some consumers who used to patronize myopic carriers will now patronize regular carriers, others who used to patronize myopic carriers will now not consume, and some who used not to consume might now patronize regular carriers because they value the increased probability of timely delivery. Consequently, we cannot state with theoretical certainty whether total consumption, and hence total truck trips, will be higher or lower after market failures have been eliminated.

Because we do not know the change in total truck trips, we cannot say for sure whether the total number of truck crashes will be less after the market failures have been eliminated. However, it would seem almost certain that the number will fall as many former customers of myopic carriers switch to regular carriers (and others drop out of the market), and regular carriers offer greater safety than they did when there were market failures present. Of course, bystanders to truck crashes still suffer an uncompensated externality, unless the revenues from the fines are distributed to bystanders.

\section{Modeling a Minimum Safety Standard}

The second public policy countermeasure we will analyze is one of the most widely used. This is the imposition of a minimum safety standard, which will be denoted as $\underline{S}$. Initially, we will assume that omnipresent government inspection removes all carriers offering less than $\underline{S}$ from the market. ${ }^{7}$ Later we will consider imperfect enforcement of the standard. Inspections occur at the start of each period. This will be a recurring expense due to the possibility of entry by sub-standard carriers. Initially we will analyze the situation where inspections are funded from general taxation. Later we will investigate the effect of funding inspections from a levy on the trucking industry. The effect of the standard on specific commodities will depend on the values of $S_{j 1}{ }^{\#}$ and $S_{j 2}{ }^{\#}$ relative to $\underline{S}$. Commodities will fall into one of four categories. 


\subsection{Commodities where $\underline{S}$ is at or below $S_{j 1}{ }^{\#}$}

The standard has no effect on the market for commodities where the minimum standard is at or below the safety level of myopic carriers.

\subsection{Commodities where $\underline{S}$ is between $S_{j 1}{ }^{\#}$ and $S_{j 2}{ }^{\#}$}

As soon as $\underline{S}$ is binding on $S_{j 1}{ }^{\#}$ there will be gainers and losers. Myopic carriers will continue to exist, but they will be forced to adopt a higher, non-cost minimizing, level of safety. The rate charged by myopic carriers will now be given by:

$$
t_{j 1}(\underline{S})=c_{j 1}(\underline{S})>c_{j 1}\left(S_{j 1}{ }^{*}\right) .
$$

Of course shippers employing myopic carriers do get an offsetting benefit in that they only need to make provision for an expected cargo loss of $(1-\underline{S}) D_{j}$ rather than $\left(1-S_{j 1}{ }^{*}\right) D_{j}$ on each trip. For a marginal increase in the minimum safety level, the marginal cost of contracting with a myopic carrier from the perspective of the shipper will be negative when $\underline{S}$ is in the range between $S_{j 1}$ \# and the level of safety that minimizes the function $l_{j}(S)+\left(1-S_{j}\right)\left(H_{j}+D_{j}\right)$, and then positive when $\underline{S}$ is greater than that level.

Equation (9) tells us that the rate charged by regular carriers will fall. The intuition is that the rate charged by myopic carriers is now higher, and closer to the cost of regular carriers. Therefore the initial investment that regular carriers have to make to establish their reputation is now smaller, and hence the rate premium to recoup this initial investment is smaller. The market dynamic is that new entrant regular carriers could undercut the existing regular carriers. The incumbent carriers will have to cut their rate to stay in the market, but will suffer a loss because they will no longer be able to fully recover their initial sunk investment in establishing a reputation. Therefore, rather paradoxically, a minimum standard that is not binding on them may be vigorously opposed by incumbent regular carriers.

The effect on the overall demand system can again be illustrated using Figure 2 . As the price for delivery by regular carriage falls and the safety level stays the same, the $v_{j 02}(\theta)$ frontier will move down vertically by the amount of the price cut. For myopic carriage, the slope of the $v_{j 01}(\theta)$ frontier will get steeper because the safety level of myopic carriers is now higher, but the intercept may move up or down. Inspection of equation (15) indicates that the $\theta_{j 12}$ frontier may move either to the left or the right. Consequently, the sign of the change in the demand for both of types of carriers is theoretically indeterminate. It is entirely possible that imposition of a minimum safety standard could increase the exposure of bystanders by increasing total truck trips. The fall in price for commodities delivered by regular carriers, and the improved reliability of myopic carriers will encourage some consumers who previously did not consume to now purchase. Of course, the rate of crashes will fall due to the improved safety performance by myopic carriers. 


\subsection{Commodities where $\underline{S}$ Approaches or Equals $S_{j 2}{ }^{\#}$}

For commodities where it just so happens that the minimum safety standard exactly equals the safety level of regular carriers, one type of carrier will be eliminated from the market. However, it will be the regular rather than the myopic carriers that disappear. When $\underline{S}$ equals $S_{j 2}$, both types of carriers will offer the same level of safety. In terms of reliability, consumers will become indifferent between whether the commodity is delivered by a regular or a myopic carrier. The rate charged by regular carriers falls to equal costs because there is no need to invest to establish a reputation. However, regular carriers will be undercut and displaced by myopic carriers. In fact, the elimination of regular carriers will set in before $\underline{S}$ equals $S_{j 2}{ }^{\#}$. This will occur when:

$$
\theta^{\max }=\frac{p_{j 2}\left(\underline{S}, S_{j 2}^{\#}, \alpha\right)-p_{j 1}(\underline{S})}{S_{j 2}^{\#}-\underline{S}} .
$$

The demand system will be characterized by just one frontier in Figure 2. This is the $v_{j 01}(\theta)$ frontier, with an intercept given by $t_{j l}(\underline{S})$, and a slope given by $\underline{S}$. Consumers above and to the right will purchase the commodity delivered by myopic carriers, and those below and to the left will not consume the commodity. This result is rather a mixed bag for bystanders. We cannot say with certainty whether total truck traffic for this commodity will increase or decrease compared with situation with market failure. The good news is that the average crash rate has improved because the myopic carriers now are operating with the same degree of safety that the former regular carriers did. The bad news is that bystanders now do not get any compensation for harms, because no carriers have made provision to pay compensation and declare bankruptcy to avoid payment.

\subsection{Commodities where $\underline{S}$ is greater than $S_{j 2}{ }^{\#}$}

As with the situation described in the previous section, only myopic carriers survive in the marketplace when $\underline{S}$ exceeds $S_{j 2}$. . As the standard is increased, carriers move further away from their cost-minimizing level of safety. Costs will increase, and as the rate now equals cost, the rate will increase. The intercept of the $v_{j 0 l}(\theta)$ frontier will shift upwards, but it will have a steeper slope as the reliability of delivery is now greater. The effect on overall demand for transportation is unclear as some consumers with low valuations of reliability will now be priced out of the market, but it is possible that other consumers with low reservation values but moderate sensitivity to reliability may now decide to consume. It will all depend on the nature of the relationship between the safety provided and costs, and the distribution of values of $v_{j}$ and $\theta_{j}$ across consumers. While the effect on exposure to crashes is indeterminate, bystanders will benefit from a lower crash rate. Of course, they continue to receive no compensation for their losses.

Ultimately, the minimum safety level could be raised so high for a particular commodity, that:

$$
v_{j}^{\max }+\theta_{j}^{\max } \underline{S}-M_{j}-t_{j l}(\underline{S})=0,
$$

and there is no longer any demand by consumers for commodity $j$. 


\subsection{Enforcement Costs}

Inspections occur at the start of each period. While omnipresent enforcement requires every carrier to be inspected, we would expect that the total cost of inspections is an increasing convex function of $\underline{S}$, rather than a fixed amount. There are two reasons. The first is that there will only be a demand for sub-standard service for commodities where $\underline{S}>S_{j 1}$. Inspections of carriers who transport commodities where $\underline{S} \leq S_{j 1}$ \# can be much more perfunctory and shorter. As $\underline{S}$ is increased, more commodities will be affected, and the average length of inspections will increase. The second is that as $\underline{S}$ is raised, inspections will need to be more detailed and cover more vehicle components and more aspects of driver qualifications.

\subsection{Setting an Optimal Minimum Safety Standard}

We will delay discussing the welfare implications or the optimal setting of the minimum standard because the setting of a safety standard in isolation clearly has a major flaw in that for some commodities the regulation promotes myopic carriers at the expense of regular carriers. Bystanders, while enjoying less risk, are left without any compensation for their losses. Consequently the compulsory holding of insurance for third-party losses would seem to be an essential part of any market intervention of this type.

\section{Third Party Insurance combined with a Minimum Safety Standard}

\subsection{Setting Insurance Rates}

The holding of insurance is an extremely complex and multi-faceted issue (see Shavell, 2004, for a review), and one that is largely beyond the scope of this paper. For the sake of space, we will just consider the case where insurance has to be held to cover damage caused to shipper's cargo and the legally recoverable harms to bystanders. That is to say $\left(D_{j}+\alpha_{j} E_{j}\right){ }^{8}$ Absent administrative expenses, regular shippers will be charged a premium of $\left(1-S_{j 2}{ }^{\#}\right)\left(D_{j}+\alpha_{j} E_{j}\right)$ and myopic carriers will be charged $\left(1-S_{j 1}{ }^{\#}\right)\left(D_{j}+\alpha_{j} E_{j}\right)$. Regular carriers will not alter their behavior because they were already taking out insurance or self-insuring by this amount. However, myopic carriers will now have to internalize the risk of claims. They will modify their cost-minimizing safety choice to equal $S_{j 2}{ }^{\#}$, and receive a lower insurance premium in return. Regular and myopic carriers will become indistinguishable.

The demand system will be characterized by just one frontier in Figure 2 . This is the $v_{j 02}(\theta)$ frontier, with an intercept given by $M_{j}+c_{j 2}\left(S_{j 2}{ }^{\#}, \alpha_{j}\right)$, and a slope given by $S_{j 2}{ }^{\#}$. Carriers do not have to invest in establishing a reputation as there is only one type of carrier in the market. Consumers above and to the right will purchase the commodity, and those below and to the left will not consume.

For insurance to work in this way, premiums have to be tailored to risk. Insurance companies would need to be able to identify the commodity carried and the carrier type (regular versus myopic). In our model, shippers can identify the type of carriers based on their reputation. Insurance companies should also be able to observe this. In addition, regular carriers have an 
incentive to reveal themselves. Consider what would happen if insurance companies could not tell the difference between regular and myopic carriers. Premiums would be set based on the weighted average of the crash rate of the two types of carriers. Regular carriers would be faced with higher premiums than the amount they would have voluntarily set aside to cover expected losses at $S_{j 2}$. They could defect to form their own insurance pool, and only myopic carriers will remain in the marketplace for commercial insurance. The premiums will adjust to reflect the fact that only myopic carriers are purchasing. As soon as this occurs, the market will adjust to remove the myopia as described above.

\subsection{Insurance and the Minimum Safety Standard}

Unlike the earlier analysis of a minimum standard, the insurance requirement results in just two categories of commodities. The first is where $\underline{S} \leq S_{j 2}$. . Commodities in this category will be unaffected by the minimum safety standard. In contrast commodities where $\underline{S}>S_{j 2}{ }^{\#}$ will witness an increased level of safety, and an increased transportation rate. In terms of the demand system in Figure 2, the sole applicable frontier is $v_{j 02}(\theta)$ which will see its intercept shift upwards, and its slope get steeper. Consequently, the sign on the effect on the overall demand for transportation is unclear. Ultimately it is possible that the minimum standard will be raised so high that some commodities will no longer be shipped.

\subsection{Setting an Optimal Minimum Safety Standard}

Only consumers of commodities where $\underline{S}>S_{j 2}{ }^{\#}$ suffer a welfare loss. For a marginal increase in the minimum standard from $\underline{S}$ to $\underline{S}^{\prime}$, consumers who continue to purchase have a welfare change given by:

$$
\theta_{i j}\left(\underline{S}^{\prime}-\underline{S}\right)-\left[c_{j 2}\left(\underline{S}^{\prime}, \alpha_{j}\right)-c_{j 2}\left(\underline{S}, \alpha_{j}\right)\right] .
$$

The first term is the valuation of the improved reliability of delivery which is set against the increased transportation cost of meeting the higher minimum standard. The welfare change may be positive or negative for individual consumers depending on their value of $\theta_{i j}$. Consumers who decide to stop consuming will suffer a loss of the net benefit they used to obtain from consuming the commodity. That is to say $v_{i j}+\theta_{i j} \underline{S}-M_{j}-c_{j 2}\left(\underline{S}, \alpha_{j}\right)$. For those attracted to consume due to the higher reliability, albeit at a higher price, they will obtain a net benefit of $v_{i j}+\theta_{i j} \underline{S^{\prime}}-M_{j}-c_{j 2}\left(\underline{S}, \alpha_{j}\right)$.

While the effect on exposure to crashes is indeterminate, bystanders will benefit from a lower crash rate. Presuming that combination of these two effects is to reduce the absolute number of crashes, the total uncompensated losses will fall. There will be a benefit equal to:

$$
\operatorname{TEUE}\left(\underline{S}, \alpha_{j}\right)-\operatorname{TEUE}\left(\underline{S^{\prime}}, \alpha_{j}\right)=\sum_{j}\left[\left(1-\alpha_{j}\right) E_{j} q_{j 2}\left(\underline{S}, \alpha_{j}\right)\right]-\sum_{j}\left[\left(1-\alpha_{j}\right) E_{j} q_{j 2}\left(\underline{S}^{\prime}, \alpha_{j}\right)\right],
$$

where this summation is over those commodities for which the minimum standard is binding. 
An optimal determination of the minimum standard will occur when the marginal losses to the consumers plus the marginal enforcement costs (which should carry a shadow value to represent the marginal cost of public funds) equals the marginal reduction in aggregate uncompensated losses to the bystanders. ${ }^{9}$ Note that now the enforcement cost include activities to ensure that carriers have adequate insurance cover in addition to checking on the preventive efforts made by the carriers.

\section{Imperfect Enforcement}

The preceding analysis assumes that omnipresent enforcement eliminates substandard and non-insurance holding carriers. In practice omnipresent enforcement is neither physically practical nor financial affordable in an industry characterized by hundreds of thousands of small carriers and considerable geographic dispersion. Imperfect enforcement is introduced by specifying a variable 0 $<\psi<1$ that measures the proportion of the carriers that are inspected at random at the start of each period.

\subsection{Commodities where $\underline{S} \leq S_{j 2}{ }^{\#}$}

For these commodities, regular carriers will not have any incentive to contravene the standard. However, there would be a market for myopic carriers to certainly avoid holding insurance and possibly produce with sub-standard safety (depending on how $\underline{S}$ is set in comparison to $S_{j 1}{ }^{\#}$ ). Myopic carriers will supply safety of $S_{j 1}{ }^{*}$. Shippers will again have the choice of regular and myopic carriers, and a reputation model will be needed so that shippers can make an informed choice. Consequently as soon as imperfect enforcement allows some myopic carriers to re-enter the market, the price for delivery by regular carriers will increase from $M_{j}+c_{j 2}\left(S_{j 2}{ }^{\#}, \alpha_{j}\right)$ up to the that described by equations (9) and (10) which incorporate the rate premium to recover the initial investment in establishing a reputation for regular carriage.

Referring to the representation of the demand system in Figure 2, we observe that consumers located in areas V and VI do not purchase, those in areas III and IV purchase the commodity delivered by a regular carrier, and the potential market for myopic carriers is shown by areas I and II. Imperfect enforcement allows a proportion (1- $\psi)$ of the consumers in areas I and II to actually obtain the commodity delivered by a myopic carrier. For the remainder of the consumers who are not so "lucky," the remaining consumers in area II will purchase the commodity that is delivered by a regular carrier, and the remaining consumers in area I will not purchase.

\subsection{Commodities where $\underline{S}>S_{j 2}{ }^{\#}$}

For these commodities, one has to make assumptions about how regular carriers will act. On the face of it, they have incentives to minimize cost by selecting $S_{j 2}{ }^{\#}$, and some proportion of them will escape detection and be able to do so. However, these carriers are not myopic, so a system of penalties could be put in place so that a rational regular carrier would never break the standard. Regular carriers who might consider breaking the standard would incorporate the expected value of the penalty into their pricing. If the penalty was high enough, the price of the sub-standard quality $S_{j 2}{ }^{\#}$ will become sufficiently high that no consumers would choose to purchase. Denoting the penalty as $Y$, consumers would not patronize a standard-breaking regular carrier if: 


$$
\psi Y>\left[t_{j 2}\left(S_{j 1}^{\#}, \underline{S}, \alpha_{j}\right)-t_{j 2}\left(S_{j 1}^{\#}, S_{j 2}^{\#}, \alpha_{j}\right)\right]-\theta_{j}^{\min }\left(\underline{S}-S_{j 2}{ }^{\#}\right) .
$$

The first term on the right hand side is the transportation rate decrease associated with moving to the cost minimizing safety level. The second term indicates the valuation placed by the least sensitive consumer on the lower level of safety. The expected value of the penalty has to be larger than the reduced transportation rate less the smallest possible consumer valuation of the less reliable service.

If there are multiple commodities for which $\underline{S}>S_{j 2}$, there will be multiple penalty levels assuming a similar probability of detection. If, in practice, only one penalty amount is possible in the legal system, the penalty should be set at the maximum value defined by equation (31) over the relevant commodities.

Because of the penalties, no regular carriers will choose to break the standard. Because $\underline{S}>$ $S_{j 2}{ }^{\#}$, the rate charged by regular carriers will rise. In part this is due to the higher costs associated with higher-than-cost-minimizing levels of safety. In part this is because new entrant regular carriers will have to incur a higher initial investment to establish a reputation because there is now larger spread between the rate charged by myopic carriers and the cost of providing regular carriage. ${ }^{10}$

By definition, myopic carriers will ignore expected penalties. Consequently, these carriers will act as described for the case where $\underline{S} \leq S_{j 2}$. . The system of demand will be similar to that described in the previous section, excepting that the $v_{j 02}(\theta)$ frontier will see its intercept shift upwards, and its slope get steeper, and the $\theta_{j 12}$ frontier may move either to the left or the right.

\subsection{Setting an Optimal Imperfectly Enforced Minimum Safety Standard}

The government will now have to choose the pair of values of $\psi$ and $\underline{S}$ that maximizes social welfare, and then set $Y$ accordingly based on equation (31). A crucial determinant will be the enforcement cost functions for $\psi$ and $\underline{S}$. The increasing and convex nature of the relationship between $\underline{S}$ and enforcement cost was discussed earlier. There is likely to be a similar relationship between $\psi$ and enforcement costs as higher levels of enforcement will require authorities to find and inspect the craftiest and most geographically remote carriers.

\section{Funding the System of Inspections from the Industry}

The previous analyses have assumed that inspections are funded from general taxation. The system of penalties generates no revenue because regular carriers decide not to contravene the minimum standard, and detected myopic carriers will use bankruptcy protection to avoid payment of the penalty. The government could recoup the enforcement costs from the industry by assessing a uniform fee that must be paid by each carrier. We will denote the per-carrier fee as $Z(\underline{S})$. This is payable each period, and might take the form of a fuel tax surcharge.

In a world of imperfect enforcement, the price of commodities delivered by either myopic or regular carriers will increase by this uniform amount. In terms of Figure 2, the $v_{j 01}(\theta)$ and $v_{j 02}(\theta)$ 
frontiers will both shift upwards parallel to themselves by the same amount, and the $\theta_{j 12}$ frontier will be unchanged. All consumers will lose out, and some will decide not to consume. Bystanders benefit because the amount of truck traffic falls. Funding the inspections from within the industry, as opposed to general taxation, provides additional benefits to bystanders.

\section{The Political Economy}

The emotive nature of truck safety often means that countermeasures are decided upon in a political economy rather than by a neutral social planner. In voting systems such as the median voter rule (Downs, 1957) a policy that obtains a simple majority triumphs without regard to the magnitude of the gains and losses sustained by individuals. Insights into the political process can be obtained from the structural model because it defines who gains and who loses from each countermeasure.

\subsection{The Post-Crash Fine and Secondary Liability Versus the Minimum Standard}

The first choice that will be analyzed is the decision between implementing a policy of the post-crash fine and liability reform versus adopting an imperfectly enforced minimum safety standard that is deployed in conjunction with a third-party liability requirement and a penalty for non-compliance. On the basis of the ultimate market outcome, and the costs involved in implementation, the former would seem to be the socially superior option. However, it would seem that in practice the latter has been the favored policy option.

The reasons for this can be discerned by looking at the welfare rankings of the two policy regimes by the various agents in the model. The preferences of consumers can be analyzed with the help of Table 1. This table summarizes the prices and levels of reliability available to consumers in the market with failures, and under the two policy options.

Consider first consumers of commodities delivered by regular carriers that, if the minimum standard were implemented, provide a level of safety greater than or equal to the standard $\left(\underline{S} \leq S_{j 2}{ }^{\#}\right)$. The minimum standard does not affect the price and reliability of delivery. In contrast the consumers may be worse off under the post-crash fine and secondary liability if the level of the fine exceeds the eliminated premium to compensate for establishment of a reputation (and adjusted for the higher level of reliability). Consumers of this type may tend toward favoring the minimum standard.

Turning to consumers of regular carriers hauling commodities where the minimum standard would be binding $\left(\underline{S}>S_{j 2}{ }^{\#}\right)$, it is not clear which policy regime would leave them better off.

Consumers who purchase goods delivered by myopic carriers unambiguously favor the minimum standard when imperfect enforcement allows a subset of the consumers to still obtain such myopic service. In contrast the fine and secondary liability eliminates the supply of myopic service.

Shippers earn zero profits in this model. Therefore any shipper preferences will presumably hinge on the equilibrium number of units of the various commodities sold. This is because the 
policy that eliminates the most truck miles will also eliminate the greatest number of shippers. In general the fine and secondary liability will reduce truck miles the most, and therefore one might expect shippers groups to favor the minimum standard. This will be especially true for shippers of commodities where $\underline{S} \leq S_{j 2}{ }^{\#}$. One would imagine that shippers' groups would be particularly opposed to the post-crash fine which would require shippers and their customers to internalize a legally irrecoverable externality imposed on bystanders.

Trucking companies would have similar preferences to shippers. They earn zero profits, but the different policy regimes would affect the number of carriers in the market. In addition trucking companies would have a particular aversion to the fine and secondary liability as it would eliminate the rate premium associated with a high quality reputation. Carriers that had already established a reputation would suffer a capital loss.

Employees of trucking companies presumably would have similar preferences to carriers in some regards. They would certainly be motivated to oppose policies that would reduce the size of the industry and the number of drivers. (In this model, drivers are fully compensated for crashrelated injuries, and in theory are indifferent on the safety level of the industry. Of course, one would imagine that they would prefer a safer working environment, but this would require drivers to incur non-compensated harms in crashes.)

The preference of bystanders is not clear cut. The minimum standard attempts to deal with the uncompensated externality by raising $\underline{S}>S_{j 2}$ 이 for some commodities. The fine and secondary liability policy regime deals with this problem by levying a post-crash fine. If the revenue from the fine was distributed to bystanders in some fashion then they would clearly prefer this policy. However, if they did not receive any of the fine revenues then it is not inconceivable that they may prefer the minimum standard.

Probably the only party who is very clearly in favor of the post-crash fine and secondary liability are taxpayers. They certainly prefer a policy that generates revenues, rather than having to fund costly inspections.

Overall, it is easy to see why public policy has gravitated toward an expensive system of standards and inspections. Of course, this analysis is very simplified. In practice, nearly every taxpayer is likely to also be a pedestrian or highway user and exposed to truck crashes, and everybody purchases goods that are shipped by truck at some point of the supply chain. Hence every member of society is probably simultaneously a consumer, a bystander and a taxpayer. Complicating things further, most consumers purchase multiple commodities. An individual's policy preference will depend on their personal situation, such as the commodities they purchase, their inherent valuation of these commodities, and their exposure to truck crashes.

\subsection{The Effect of the Funding of Inspections}

If the funding instrument is changed so that the cost of inspections is collected from the trucking industry, the dynamic changes considerably. Taxpayers still prefer the post-crash fine and secondary liability as they obtain revenues under this policy, while the minimum standard is now 
self supporting. However, more of the shippers, consumers and trucking companies may also favor the fine and secondary liability if they have to bear the costs of the inspections. Politically, requiring the industry to bear the cost of inspections may help tilt the balance in favor of the welfare-superior fine and secondary liability.

\subsection{Setting the Minimum Safety Standard}

Assuming that the minimum safety standard is the selected policy, how would the political economy determine the level at which to set the standard and/or the effectiveness of the enforcement? Bystanders will always prefer a higher and more stringently enforced minimum standard to a lower or less stringently enforced minimum standard.

In opposition is a wide-ranging coalition that would prefer to set the standard and level of enforcement as low as possible. If the inspections are funded from general tax revenues, taxpayers will prefer as low a minimum standard as possible, and the smallest proportion of carriers inspected, to avoid the additional taxation necessary to enforce higher minimum standards. Consumers of commodities with $\underline{S}>S_{j 2}{ }^{\#}$ will be opposed to any standard that requires them to pay higher prices (albeit with a greater level of reliability). Also opposed are the shippers and carriers who fear that the contraction of the trucking market will force them out of business.

\section{Conclusions}

This paper presents a structural model in which trucking safety is determined in conjunction with prices and output. This model can be used to reveal the mechanisms and the full effects of safety market failures caused by uncompensated externalities imposed by crashes on bystanders, and the myopic decisions by some trucking managers to ignore the increased probability of crashes that may result from cost savings in driver training and vehicle maintenance. The model can also be used as a tool for analyzing potential public policy countermeasures, and illuminating the effects of these policies on safety and the welfare.

The model predicts that differences in prevention costs and the consequences of accidents lead to levels of safety that vary in predicable ways across commodities. In addition the magnitude of the possible crash externalities associated with a commodity determines the market opportunities for myopic carriers. Other things being equal, commodities with the highest levels of externalities have the greatest potential for myopic behavior. That said, the model predicts that non-myopic carriers of commodities with the greatest externalities tend to have the highest level of safety. Commodities that have negligible crash externalities tend to be transported at relatively lower levels of safety; even by carriers who are not myopic.

This paper contrasts two public policy responses: a post-crash fine and secondary liability on the shipper versus a minimum safety standard. The former removes all of the market failure, and would seem to do so in a low-cost and practical manner. The latter policy is more complex. In contrast to the traditional literature, where different countermeasures are sometimes deployed as substitutes or sometimes as complements (see, of example, Kolstad et al, 1990), our model finds that the truck safety market needs the minimum safety standard to be deployed in conjunction with a 
requirement for carriers to hold third-party insurance, and the imposition of penalties for noncompliance.

The large enforcement cost of the latter policy suggests that this would not be the preferred policy from the point of view of a social planner. However, in reality the political process seems to have favored the minimum standard. The structural model, that exposes who gains and who loses from policy interventions, provides the necessary insights into the overwhelming political constituencies that combine to make the minimum standard the favored public policy, and seek to keep the minimum standard as low as possible.

\section{Acknowledgments}

This paper has benefited considerably from the reviews by two very thorough referees, and conversations with my colleagues Robert Porter, and especially John Panzar. However, I bear the blame for any remaining errors.

\section{References}

Downs, A., 1957. An Economic Theory of Democracy. Harper and Row, New York.

Horrace, W.C., Keane, T.P., 2004. Ranking and selection of motor carrier safety performance by commodity. Accident Analysis and Prevention 36, 953-960.

Klein, B., Leffler, K.E., 1981. The role of market forces in assuring contractual performance. Journal of Political Economy 89, 615-641.

Kolstad, C.D., Johnson, G.V., Ulen, T.S.,1990. Ex post liability for harm vs. ex ante safety regulation: Substitutes or complements? American Economic Review 80, 888-901.

Moses, L.N., Savage, I., 1997. A cost-benefit analysis of United States motor carrier safety programs. Journal of Transport Economics and Policy 31, 51-67.

Royal Society, 1983. Risk Assessment: A Group Study Report. Royal Society, London.

Saccomanno, F., Shortreed, J., 1996. Truck Safety: Perceptions and Reality. Institute for Risk Research, University of Waterloo, Waterloo, Ontario.

Samuelson, P.A., 1952. Spatial price equilibrium and linear programming. American Economic Review 42, 283-303

Savage, I., 1999. The economics of commercial transportation safety. In Gómez-Ibáñez, J.A., Tye, W.B., Winston, C., (Eds.), Essays in Transportation Economics and Policy: A Handbook in Honor of John R. Meyer, Brookings Institution, Washington D.C. 
Shapiro, C., 1983. Premiums for high quality products as returns to reputations. Quarterly Journal of Economics 98, 659-680.

Shavell, S., 2004. Foundations of Economic Analysis of Law. Harvard University Press, Cambridge, Mass.

\section{Footnotes}

${ }^{1}$ This paper concentrates on the truckload rather than the less-than-truckload (LTL) segment of the industry because differences in the cost and demand parameters across commodities produce differential safety outcomes. The LTL business inherently combines different cargoes for line-haul transportation, and consequently would be of less interest from a safety modeling perspective.

${ }^{2}$ Two other safety market failures that are often found in transportation - imperfect competition and asymmetric information - are not dealt with in this paper. There is empirical justification for this. Truckload trucking is characterized by many firms competing with each other, and is probably the mode that most closely approximates perfect competition. Freight shippers are also dispassionate repeat customers of trucking firms and are not susceptible to the types of cognitive failures associated with passenger transportation where travelers have a hard time evaluating risk.

${ }^{3}$ It is possible that there may also be consumers located locally at A. In the model of inter-regional trade used in this paper, the price charged to these consumers will not depend on the nature of the trucking market between A and B. Therefore, for simplicity, consumers are located solely at B.

${ }^{4}$ For tractability of the model, it is assumed that no individual shipper can take any actions that increase or decrease the probability of a crash or modify the repercussions. That is to say, all shippers of a commodity use identical packaging.

${ }^{5}$ One hesitates to describe this equilibrium with market failures removed as "first best" because we do not permit some regular carriers to offer greater than cost-minimizing safety, at a higher rate, to consumers willing to pay for a greater reliability of delivery.

${ }^{6}$ One will note that existing regular carriers will suffer a capital loss from implementation of this policy because they can no longer fully recoup their initial investment in establishing a reputation. This will be discussed further in the next section.

${ }^{7} \mathrm{~A}$ minimum standard expressed in these terms is referred to as a performance standard. This is useful in a world where the regulator can observe the safety performance of each carrier. Because this is difficult to do in the trucking industry where many carriers are small and crashes are infrequent, the minimum performance is translated into specification standards for a subset of inputs that affect safety, such as equipment specifications and employee qualifications, which can be observed and monitored for compliance.

${ }^{8}$ If the cargo damage is excluded from insurance, myopic carriers will minimize cost excluding cargo damage. Shippers will include the expected cargo damage in their carrier choice decisions and find that myopic carriers will cost more than regular carriers, and hence myopic carriers will be 
excluded from the market. Of course, this might be a useful tactic for the government to deploy.

9 This presumes that a regular benefit-cost standard can be used. There are circumstances when society might set an absolute minimum standard to eliminate "intolerable" risks that no person should be exposed to (see Royal Society, 2003).

${ }^{10}$ There is an interesting market dynamic here. Incumbent regular carriers have already established a reputation at a lower initial investment cost than potential new entrants. This may create a barrier to entry. If new entrants buy the assets and reputation of exiting regular carriers it is possible that the price of regular carriage will only increase due to the higher costs, but the rate premium to recoup the initial investment will remain unchanged. 
Fig. 1. Cost minimizing safety choice by a regular carrier

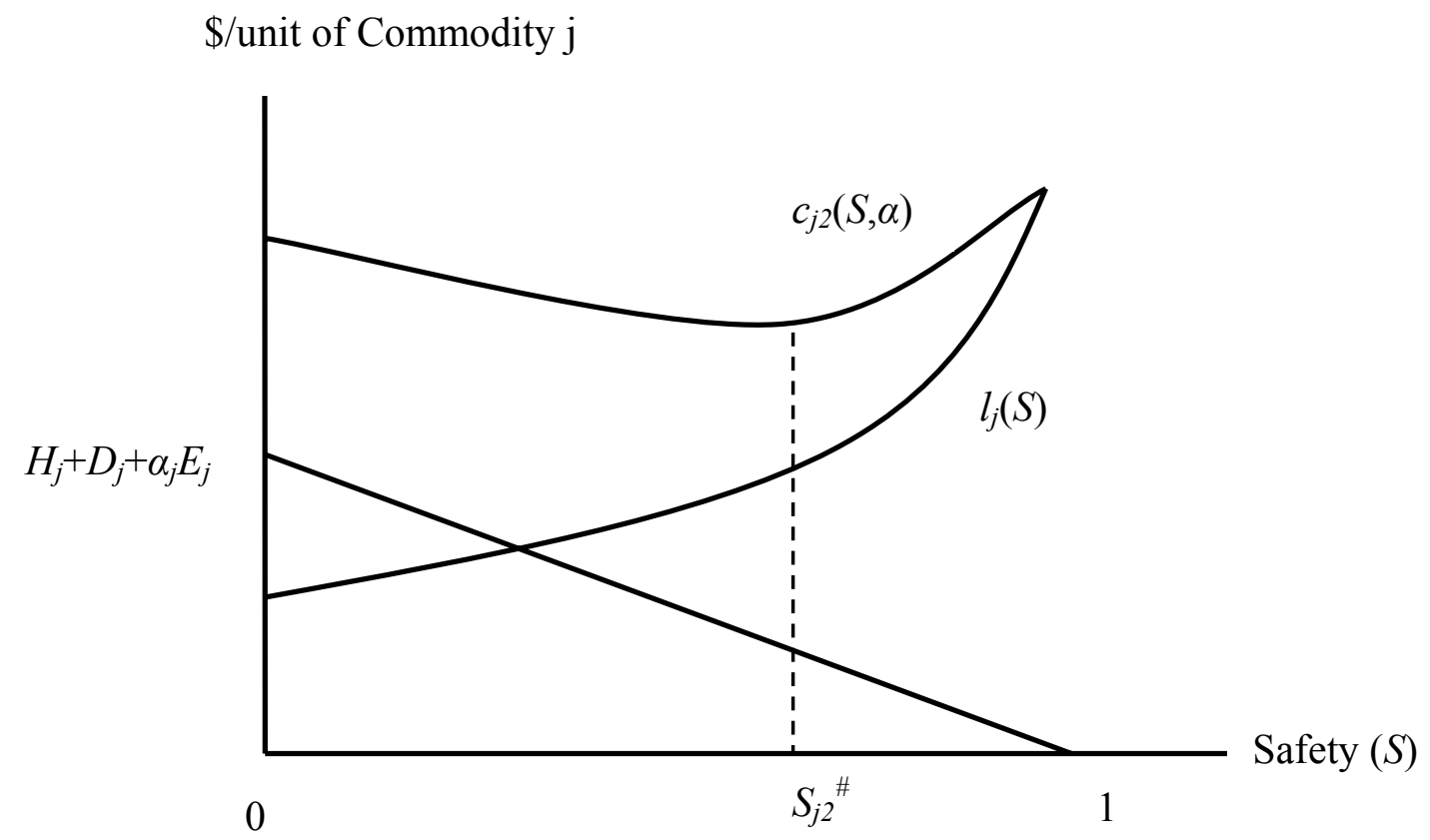


Fig 2. Consumer choice between not consuming and purchasing commodity $j$ delivered by regular or myopic carriers

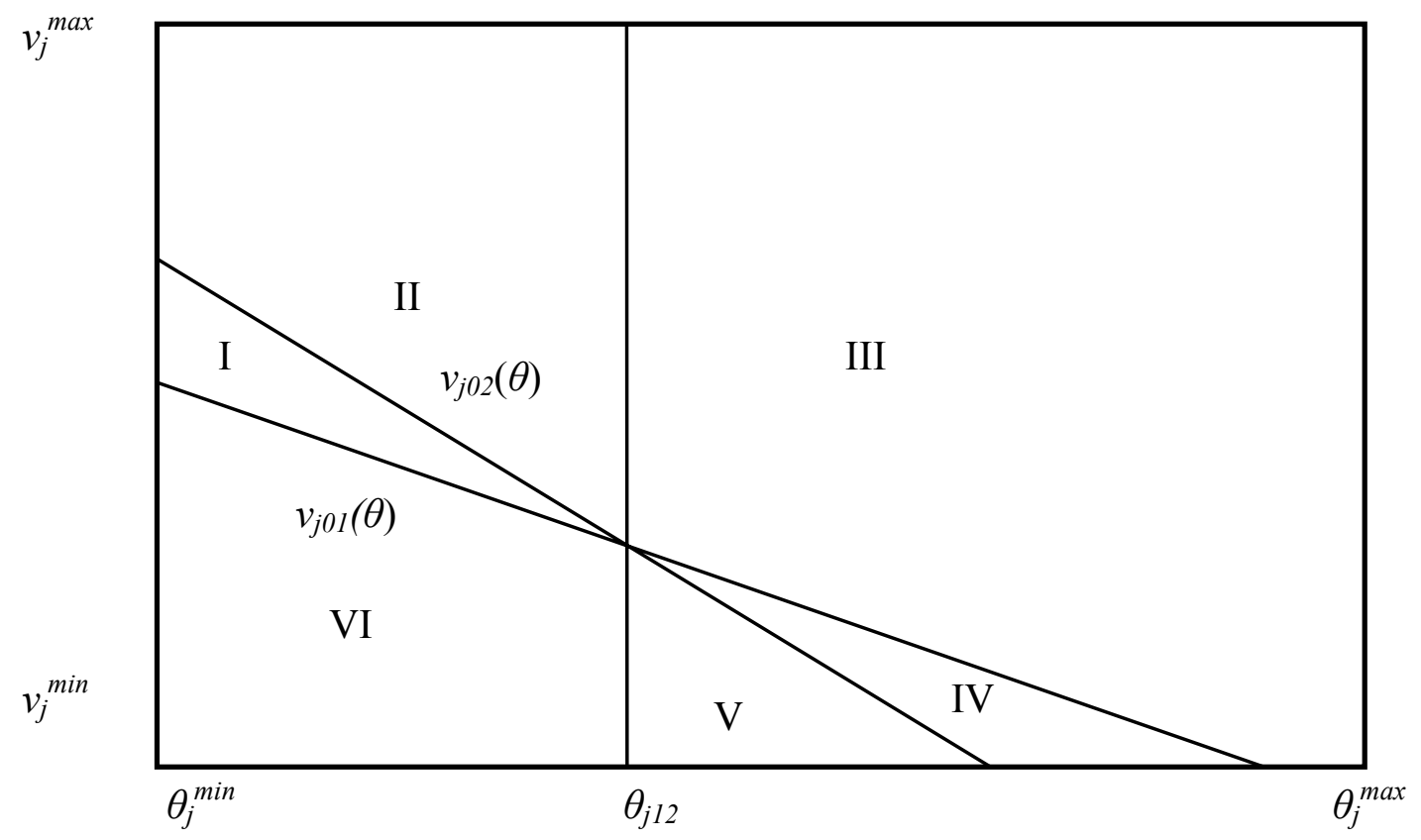


Table 1

Delivered price and reliability in different scenarios

\begin{tabular}{|c|c|c|c|c|}
\hline & $\begin{array}{l}\text { With No Intervention to } \\
\text { Correct the Market failure }\end{array}$ & $\begin{array}{l}\text { Post-Crash Fine and } \\
\text { Secondary Liability }\end{array}$ & $\begin{array}{l}\text { Imperfectly Enforced } \\
\text { Minimum Standard } \\
\text { when } \underline{S} \leq S_{j 2}^{\#} \\
\text { Note }(a)\end{array}$ & $\begin{array}{l}\text { Imperfectly Enforced } \\
\text { Minimum Standard when } \\
\underline{S}>S_{j 2}^{\#} \\
\text { Note }(a)\end{array}$ \\
\hline $\begin{array}{l}\text { Delivered price by } \\
\text { Regular Carriers } \\
\text { Note (b) }\end{array}$ & $\begin{array}{l}M_{j}+c_{j 2}\left(S_{j 2}{ }^{\#}, \alpha_{j}\right) \\
+r\left[c_{j 2}\left(S_{j 2}{ }^{\#}, \alpha_{j}\right)-t_{j 1}\left(S_{j 1}{ }^{\#}\right)\right]\end{array}$ & $M_{j}+c_{j 2}\left(S_{j 2}{ }^{*}, \alpha_{j}=1\right)$ & \multirow{2}{*}{$\begin{array}{l}\text { Same as with no } \\
\text { intervention }\end{array}$} & $\begin{array}{l}M_{j}+c_{j 2}\left(\underline{S}, \alpha_{j}\right) \\
+r\left[c_{j 2}\left(\underline{S}, \alpha_{j}\right)-c_{j 1}\left(S_{j 1}^{\#}\right)\right] \\
\operatorname{Note}(c)\end{array}$ \\
\hline $\begin{array}{l}\text { Reliability of Regular } \\
\text { Carriers }\end{array}$ & $S_{j 2}{ }^{\#}$ & $S_{j 2}{ }^{*}>S_{j 2}{ }^{\#}$ & & $\underline{S}$ \\
\hline $\begin{array}{l}\text { Delivered price by } \\
\text { Myopic Carriers } \\
\text { Note (b) }\end{array}$ & $M_{j}+\left(1-S_{j 1}^{\#}\right) D_{j}+t_{j 1}\left(S_{j 1}^{\#}\right)$ & \multirow{2}{*}{$\begin{array}{l}\text { Eliminated from } \\
\text { Market }\end{array}$} & \multirow{2}{*}{\multicolumn{2}{|c|}{$\begin{array}{l}\text { Same as with no intervention, but the supply of goods } \\
\text { delivered by myopic carriers is rationed due to } \\
\text { imperfect enforcement. }\end{array}$}} \\
\hline $\begin{array}{l}\text { Reliability of Myopic } \\
\text { Carriers }\end{array}$ & $S_{j 1}^{\#}$ & & & \\
\hline
\end{tabular}

Notes:

(a) The imperfect-enforced minimum standard includes a third-party insurance requirement and a penalty for non-compliance.

(b) This table assumes that the cost of enforcement is funded by general taxation. If inspections are funded by a tax on the industry, the price of delivery by both regular and myopic carriers in the final two columns will increase by $Z(\underline{S})$.

(c) See text note 10 regarding a discussion of the value of the third term. 